\title{
Impact of distance-learning training on substance use screening and brief intervention among health professionals and on their beliefs and attitudes toward drug use
}

\author{
Ana Paula L Carneiro ${ }^{1 *}$, Denise De Micheli ${ }^{2}$, Monica Maino², Jose Carlos Fernandes Galduroz ${ }^{2}$, Yone Moura ${ }^{3}$, \\ Paulina CAV Duarte ${ }^{4}$, Maria Lucia O Souza-Formigoni ${ }^{2}$
}

From International Network on Brief Interventions for Alcohol and Other Drugs (INEBRIA) Meeting 2011 Boston, MA, USA. 21-23 September 2011

Screening for alcohol and other drug (AOD) use followed by brief intervention (SBI) represents a useful tool for health professionals, since most people who are in the early stages of substance-related problems receive no guidance before developing significant consequences. In order to disseminate the techniques of SBI among Brazilian health professionals, the National Secretary on Drug Policy (SENAD), in partnership with the Drug Dependence Unit of UNIFESP, developed the distance learning program SUPERA. The aim of this study was to assess whether health professionals who participated in SUPERA changed their beliefs and behaviors related to AOD after completing the training. Health professionals from the Brazilian public health network who successfully completed the course $(\mathrm{N}=1062)$ participated in the study. They answered a questionnaire on their beliefs and attitudes regarding AOD use before and after the course. After completing it, 91\% of participants reported feeling more able to use SBI techniques than before, and $60 \%$ (compared with 37\% pre-training) reported believing that demonstrating concern for patients' AOD use could help reduce their consumption. Seventy-three percent (versus $50 \%$ pre-training) believed in the importance of BI to reduce AOD use, and 60\% (versus 30\%) reported believing in patients' capacity to reduce AOD use. Most of the participants (66\% after training versus $28 \%$ before) considered themselves to have an adequate level of knowledge about AOD use, and $83 \%$ (versus 22\%) reported high confidence

'Department of Biological Sciences, Federal University of São Paulo, São Paulo, Brazil

Full list of author information is available at the end of the article in their ability to detect AOD use. These data indicate positive changes in health professionals' knowledge and attitudes regarding AOD use after the course, suggesting that distance learning is adequate to train health professionals in SBI.

\section{Author details}

'Department of Biological Sciences, Federal University of São Paulo, São Paulo, Brazil. ${ }^{2}$ Department of Psychobiology, Federal University of São Paulo, São Paulo, Brazil. ${ }^{3}$ Center of Information on Psychotropic Drugs, Federal University of São Paulo, São Paulo, Brazil. "Brazilian National Secretariat for Policies on Drugs, Rio de Janeiro, Brazil.

Published: 9 October 2012

\section{doi:10.1186/1940-0640-7-S1-A87}

Cite this article as: Carneiro et al: Impact of distance-learning training on substance use screening and brief intervention among health professionals and on their beliefs and attitudes toward drug use. Addiction Science \& Clinical Practice 2012 7(Suppl 1):A87.

Submit your next manuscript to BioMed Central and take full advantage of:

- Convenient online submission

- Thorough peer review

- No space constraints or color figure charges

- Immediate publication on acceptance

- Inclusion in PubMed, CAS, Scopus and Google Scholar

- Research which is freely available for redistribution 